\title{
Netativismo: problematizando o mito do Estado-nação nas redes digitais
}

\author{
Erick Roza ${ }^{1}$ \\ Gustavo Carbonaro ${ }^{2}$
}

\begin{abstract}
Resumo: O objetivo deste trabalho é discutir em que medida as redes digitais questionam a legitimidade do mito e da narrativa do Estado-nação. Para isso, desenvolvemos um pensamento sobre as transformações na ideia de Estado-nação como comunidade imaginada capaz de criar uma coincidência entre comunidade cultural e política. Nesse percurso, recuperamos conceito caro a esse tipo de estudo, a saber: a invenção das tradições. Na sequência, analisamos o período de consolidação do mito nacional nas sociedades modernas coincidente com a ascensão da burguesia ao poder, que encontra no Estado-nação uma forma de legitimar sua nova posição social, manipulando fatos passados e "inventando" tradições para criar narrativas históricas que representassem toda sociedade. A ilusão da comunidade nacional foi materializada e internalizada no imaginário coletivo com tamanha força, que permanece até hoje como parâmetro de organização social em todo o mundo. Argumentaremos que a própria definição de Estado (entendido como sistema pelo qual se exerce a gestão dos territórios, populações, fronteiras e sua economia) é colocada à prova pelos fluxos informativos e pelas redes digitais que fazem circular ideias, ações e recursos de uma nação a outra em poucos segundos. A tecnologia não reconhece fronteiras artificiais organizadas para gerir esses espaços de dominação entre os homens e nem mesmo seus diversos subprodutos na modernidade, partidos, sindicatos, burocracia, eleições representativas e também suas narrativas. Em resumo, é a tensão entre a forma Estado e a potência das redes digitais junto do netativismo que debatemos aqui.
\end{abstract}

Palavras-chave: Netativismo. Estado-nação. Narrativa. Mito. Redes digitais.

\begin{abstract}
The purpose of this paper is to discuss to which extent the digital networks question the legitimacy of the myth and narrative of the Nation-state. For this, we developed a thought about the changes in the idea of nation-state like an imagined community capable of creating a coincidence between cultural and political community. In this course, we recover an important concept to this type of study, namely: the invention of traditions. Following, we analyze the period of consolidation of the national myth in modern societies. It coincides with the rise of the bourgeoisie to power, which finds in the nation-state a way of legitimizing its new social position, manipulating past facts and "inventing" traditions to create historical narratives that represented the society. The illusion of the national community has been materialized and internalized in the collective imagination with such force that it remains to this day as a parameter of social organization throughout the world. We argue that the very definition of the State (understood as the system through which territories, populations, borders and their economy are managed) is put to test by the information flows and the digital networks that make ideas, actions and resources circulate from one nation to another in a few seconds. Tech-
\end{abstract}

1 Doutor em Ciências da Comunicação pela USP. E-mail: erick.roza@gmail.com.

2 Doutorando no PPGCOM da Universidade de São Paulo e Senior Partnership Officer

- Latin America do King's College London. E-mail: tatocarbonaro@gmail.com 
nology does not recognize artificial boarders organized to manage these spaces of domination between men. It also does not recognize its various by-products: parties, unions, bureaucracy, representative elections and also their narratives. In short, we intend to discuss the tension between the State form and the power of the digital networks and the net-activism.

Keywords: Net activism. Nation-state. Narrative. Myth. Digital networks.

\section{Estado, narrativas e redes digitais}

A intensa presença tecnológica na sociedade contemporânea altera, significativamente, nossa presença no mundo. Dentre as muitas fronteiras que são questionadas a partir da organização da sociedade em rede, a divisão política e social baseada no Estado-nação ainda perdura como a mais relevante de nossos tempos, ainda que cada vez mais fragilizada. A tecnologia não reconhece divisões artificiais organizadas para gerir esses espaços de dominação entre os homens nem mesmo seus diversos subprodutos na modernidade, como partidos, sindicatos, burocracia e eleições representativas. É essa tensão entre a narrativa que permite a materialidade do Estado e a potência das redes digitais e do netativismo que debatemos aqui.

O uso do termo Estado-nação para especificar a fusão entre comunidade política e comunidade cultural consolidou-se [1] entre o final do século XVIII e meados do XIX, com a ascensão da burguesia ao poder e a conclusão do ciclo revolucionário iniciado em 1789 [2]. Ao estabelecer-se no poder, a nova classe dominante legitima sua posição social por meio do Estado-nação, apresentando-se como agente de poder capaz de despertar o mundo das trevas da Idade Média por meio da manipulação de fatos passados e da "invenção de tradições" que, segundo Hobsbawm (2002, p. 9), "visam inculcar certos valores e normas de comportamento através da repetição, o que implica, automaticamente, uma continuidade em relação ao passado”.

O Estado-nação é, portanto, uma entidade ilusória ou, como define Bobbio (1998, p. 797), apenas o "reflexo na mente dos indivíduos de uma situação de poder". "Mais do que inventadas”, como afirma Lilia Moritz Schwarcz (2009, p. 10) na apresentação do clássico Comunidades imaginadas de Benedict Anderson, “nações são ‘imaginadas', no sentido que fazem sentido para a 'alma' e constituem objetos de desejos e projeções”. 
A ideia de comunidade e compartilhamento cultural, que já existia nas relações sociais em outro contexto, normalmente ligadas a pequenos grupos, é amplificada até as fronteiras políticas determinadas pelo Estado recém-formado. A nação "é imaginada como uma comunidade porque, independentemente da desigualdade e da exploração efetivas que possam existir dentro dela, a nação sempre é concebida como uma profunda camaradagem horizontal", escreve Benedict Anderson (2009, p. 34). O problema é que, como alerta Bauman (2003, p. 9), a comunidade "é o tipo de mundo que não está, lamentavelmente, a nosso alcance - mas no qual gostaríamos de viver e esperamos vir a possuir”. A busca por uma comunidade que nos proporcione proteção nos leva a uma narrativa que nos tolhe parte da liberdade, e assim foi, também, com o Estado Nacional. "Não ter comunidade significa não ter proteção; alcançar a comunidade, se isto ocorrer, poderá em breve significar perder a liberdade”, ressalta Bauman (2003, p. 10).

Houve um engajamento coletivo, de governantes e governados, para que esse compartilhamento cultural comunitário pudesse ser chamado de nação, o que colaborou para categorizar o novo conceito. A expansão dos direitos de cidadania e da infraestrutura, "que ligava partes distantes do reino e aumentava largamente a densidade das redes de comunicação com as fronteiras do Estado" (SMITH, 1997, p. 81), assim como a unificação das leis e obrigações econômicas e sociais, foram, também, fundamentais para atrair novos membros para essa comunidade ampliada. Essa ideia, antes estranha, foi ancorada na rede simbólica [3] da sociedade da época e, de certa forma, materializou-se em imagens cartográficas e símbolos nacionais - como monumentos, mapas e bandeiras - popularizados e cristalizados no imaginário coletivo pela concomitante evolução das tecnologias de comunicação.

Esses mecanismos de ancoragem e materialização - ou objetivação são as ferramentas que utilizamos para tornar familiar uma narrativa que nos é estranha, criando as representações sociais descritas por Serge Moscovici (2010). Comentando a teoria de Moscovici, Denise Jodelet (2001, p. 22) define a representação social como "uma forma de conhecimento, socialmente elaborada e compartilhada, com um objetivo prático, e que contribui para a construção de uma realidade comum a um conjunto social”. A ideia de representação social, no 
campo da psicologia, trata da formação mental de uma ideia. Essa ideia, no entanto, parte de um processo narrativo que é, ao mesmo tempo, comunicacional e discursivo. Um processo que se concretiza em outra ideia, a de signo, ainda que em um sistema semiológico segundo, como apresentado a seguir.

Pode-se afirmar que, dentro dessa perspectiva, a estrutura narrativa formada pelo mecanismo associativo das representações sociais da nação é parte da formação do mito nacional, em um espaço que Barthes (2010, p. 205) chamou de "sistema semiológico segundo". Há a apropriação de um signo (a comunidade), constituído por um significante e um significado [4] que já existem em uma cadeia semiológica anterior [5], e a impressão de um novo significado (a ideia de Estado-nação) para formar outro signo (uma comunidade nacional). "A criação do signo comunidade nacional, no segundo sistema semiológico de Barthes", descreve Carbonaro (2015, p. 34), "permite-nos definir o conjunto de representações sociais ligadas a essa comunidade imaginada como parte do percurso narrativo para a formação do mito nacional".

A sociedade, em geral, posiciona-se de forma acrítica diante do mito nacional, assimilando-o sem resistências e reagindo como se esse mito fosse "uma totalidade inextrincável de sentido e forma" e acaba vivendo o mito "como uma história simultaneamente verdadeira e irreal” (BARTHES, 2010, p. 220) [6]. Ainda segundo Barthes, o mito nada esconde e nada ostenta, ele apenas deforma, o que o torna, para a maioria das pessoas, imperceptível. Cria-se, pois, um sistema semiológico segundo para permitir a naturalização da narrativa mitológica sem estranhamento, para facilitar a sua ancoragem e objetivação. O mito transforma história em natureza, transforma "uma eventualidade em eternidade", distanciase do fato e insere-se como "se a imagem provocasse naturalmente o conceito e o significante criasse o significado" (2010, p. 223, grifos do autor). Lido dessa forma, o mito (comunidade nacional) faz com que o indivíduo seja levado a racionalizar o significado (Estado-nação) pelo significante (comunidade). O que leva à naturalização do mito é a tentação de observá-lo como um sistema indutivo, não um sistema semiológico. "Onde existe apenas equivalência, ele [o leitor do mito] vê uma espécie de processo causal: o significante e o significado mantêm, para ele, relações naturais" (BARTHES, 2010, p. 223). A falta de percepção da 
comunidade nacional como um mito justifica a força que, ainda hoje, a ideia tem na sociedade.

Entender esse mecanismo de formação do mito nacional ajuda a compreender a maneira como o conjunto de representações sociais é enraizado em nosso imaginário, formando a narrativa nacional. O Estado-nação, por meio do monopólio da violência dentro de suas fronteiras, desloca os significados e isola os campos de sentido que lhe são mais convenientes, cria e recria a narrativa mitológica da nação, impondo regras e comportamentos que estabeleçam um ambiente favorável para a reprodução de um determinado modelo mais ou menos uniforme, capaz de acelerar a reprodução do mito nacional e de gerar o próprio Estado em sua materialidade.

A comunidade imaginária do Estado se materializa, para Weber (2004) [7], por meio da gestão de condutas. Uma vez consolidado o mito nacional, o Estado passaria a agir como uma "tecnologia de gestão das condutas dos indivíduos” (WEBER, 2004, p. 58). Outro autor que reflete sobre a gestão de condutas é Michel Foucault, que coloca o Estado como técnica e tecnologia de gestão de território. A obra de Foucault possui distintas fases e uma complexidade acima dos limites que este trabalho impõe, por isso vamos nos atentar aos conceitos de dois dos textos que mais nos interessam: Vigiar e Punir e Segurança, território e população (FOUCAULT, 2004, 2008).

O movimento entre os dois textos é justamente a passagem da lógica moderna e disciplinar para a lógica da governamentalidade [8], ambas importante para a manutenção do Estado-nação. As duas lógicas são complementares e coexistem para a validação e manutenção da lógica de poder impostas a partir do mito do Estado como comunidade política e cultural.

A lógica disciplinar, que Foucault (2004) trata em Vigiar e Punir, não pode ser apreendida por uma visão jurídica do poder. Ela regula o corpo no espaço e na produção, mas também controla a trajetória de vida do indivíduo. Essa lógica, que impera no início da modernidade e do desenvolvimento capitalista, é o processo no qual produzimos a docilização dos corpos para que venham a ser corpos úteis (FOUCAULT, 2004). Já a lógica da governamentalidade, apresentada por Foucault (2008) em textos como Segurança, Território e População, 
opera pela fragmentação e separação dos espaços, que criam, ao mesmo tempo, os indivíduos e as regulações para esses mesmos espaços, colocando em jogo o governo das condutas. Se na lógica disciplinar tratava-se de fixar os indivíduos, agora se trata de controlar seus fluxos, ordenar o movimento em uma ou noutra direção. A governamentalidade é um poder de governar através da liberdade do outro.

Em um primeiro momento, a necessidade de consolidação de um projeto simbólico de organização social, baseado em tradições inventadas, impôs uma fixação das pessoas ao território, para que os laços identitários pudessem criar raízes, segundo uma lógica disciplinar. A partir daí, a gestão dos fluxos e a ordenação dos movimentos da população em uma ou outra direção - o que Foucault (2008) chama de governamentalidade - passa a ser essencial para garantir sua legitimidade. Saímos do cerceamento da liberdade para um poder que é baseado na gestão da liberdade, na gestão da conduta dos governados.

A expansão dos direitos de cidadania e da infraestrutura, "que ligava partes distantes do reino e aumentava largamente a densidade das redes de comunicação com as fronteiras do Estado" (SMITH, 1997, p. 81), assim como a unificação das leis e obrigações econômicas e sociais, foram, também, fundamentais para atrair novos membros para essa comunidade ampliada. A materialização da rede simbólica do Estado-nação não se dá apenas em monumentos, bandeiras e mapas, mas também no controle dos costumes, dos alimentos, das condições sanitárias, das mobilidades, entre outras (FOUCAULT, 2008). É aqui que encontramos o campo de intervenção do policiamento [10], por exemplo.

Esse pensamento de Foucault, do Estado como tecnologia de gestão de condutas, nega a organização estatal como unidade e o apresenta como "feixe de práticas" e formas de interação com a população. Primeiro, teríamos o governo da família, ou seja, como bem gerir os indivíduos, os bens, as riquezas e o futuro, como bem dispor as coisas na relação dos homens com os meios; aquilo que representaria a economia. Em segundo lugar, a ciência de bem governar a burocracia que executa suas ordens, a ciência de bem governar o Estado: o que viria a ser a política.

Tais divisões, que parecem deslegitimar o mito nacional, são na verdade sua grande força. Capaz de unificar sob a aura do Estado-nação todos os 
feixes de práticas, o mundo da economia e da política, o mito nacional cria uma narrativa unificadora, o que Foucault chama de "arte de governar". No lugar de burgueses, proletários e padres, a tecnologia de gestão de conduta cria o francês, o italiano, o alemão, ligados, sobretudo, ao território. Apesar de, à primeira vista, até parecer uma comunidade democrática, em que os diferentes tipos sociais se unem sob a aura da nacionalidade, essa uniformização cultural pressupõe a imposição de uma determinada narrativa - geralmente ligada à cultura erudita - sobre uma infinidade de outras pequenas narrativas de culturas populares preexistentes, utilizando-se da educação oficial e servindo-se da instrumentalização do Estado para garantir sua prevalência (GELLNER, 1993).

Assim, o que as redes digitais hoje colocam em movimento são novas formas de organizar a vida social fundadas em novos sistemas tecnológicos que afirmam práticas que abalam o Estado como agente basilar na gestão das condutas e na arte de governar, alterando a rede simbólica que o legitima. Parece-nos clara a ideia de que o Estado, como tecnologia de gestão privilegiada do social, encontra em nosso momento histórico concorrente à altura que age na direção de seu questionamento. Devemos frisar mais uma vez que com isso não queremos dizer que o Estado será substituído pelas redes digitais na gestão da vida social e sim que é essa uma das importantes características que emanam das organizações reticulares.

\section{A narrativa do Estado-nação em crise: o bitcoin e o Movimento 15M}

Um bom exemplo de uma função relevante do Estado que entra no radar da nova tecnologia animada pelas redes digitais é, talvez, a mais importante para a sua existência como o conhecemos hoje: a capacidade de gestão de um espaço econômico fundamentado no seu poder de cunhar moeda, coletar impostos e fiscalizar e avalizar os contratos, enfim, a gestão da economia e de um espaço econômico.

Para que tal capacidade seja de fato efetivada o controle da moeda no seu espaço econômico é fundamental [11]. No entanto, a surpresa é identificar que nesse universo o exemplo do bitcoin [12] também parece apresentar riscos para a soberania econômica dos Estados. Por ser uma moeda descentralizada ne- 
nhuma das economias nacionais pode controlar sua taxa de inflação ou mesmo sua valorização. Nenhum emissor centralizado "imprime" ou distribui a moeda, com isso os Estados perdem a principal arma de controle dos seus processos macroeconômicos, o controle do volume de moeda em circulação para um nível considerado ótimo de atividade econômica e emprego. Em um cenário de expansão das transações com bitcoins, grande parte da política monetária é afetada. No comércio de bitcoin não existe um mercado de juros justamente por já estar precificada a taxa de inflação de longo prazo.

Outro elemento profundamente abalado pela entrada em circulação de bitcoins é a política tributária, ou sua capacidade dos governos em arrecadar seus tributos. As transações no espaço econômico desenvolvido pelos bitcoins são anônimas, ou seja, não é possível tributar as relações comerciais que ocorrem nesse espaço por não saber quais são os agentes que de fato precisam ser tributados [13]. Esse movimento ataca diretamente a principal fonte de sustentação do Estado, sua arrecadação por impostos. Percebemos, assim, porque o bitcoin tem sido motivo de preocupações por parte das autoridades em todo o mundo.

Tão importante quanto o valor a ser tributado é o tipo de produto transacionado. Todos os Estados nacionais classificam alguns produtos como restritos ou proibidos nos seus espaços econômicos, ou seja, os Estados controlam (ou tentam controlar) o que pode e o que não pode ser comercializado. Na economia bitcoin não existe nada passível de proibição, uma vez que é muito mais difícil saber quem são as pessoas envolvidas nas transações. Esse é mais um problema trazido à tona pelas transações em moedas eletrônicas como bitcoin.

Fica evidente que esse tipo de ação está em franca oposição com o desenvolvimento do Estado moderno. Há quem possa pensar que não estamos tratando dos assuntos propostos ao divagar sobre moedas e economia. Pois devemos deixar claro que essa economia alicerçada em procedimentos que superam a função do Estado como agente regulador e organizador do espaço econômico carregam em si um potencial explosivo e que tem em grande medida escapado do poder de controle dos Estados.

Também não se enganem, insistimos sempre, ao pensar nesse tipo de moeda como algo que ataca este ou aquele Estado. É, mais uma vez, o princípio 
e a função do Estado em geral, os princípios que o preenchem de sentido que são aqui postos à prova. Democracias ou ditaduras, economias abertas ou fechadas, produtos lícitos ou ilícitos; a lógica da Economia Política, da Economia Nacional, é que sofre as consequências.

Aqui reencontramos os pontos de contato entre a narrativa que o Estado-nação produz sobre si, a relação dos indivíduos com essa narrativa e as dinâmicas sociais que a colocam em circulação e discussão. A moeda, como meio de troca generalizado, só pode funcionar com base no fundamento da confiança no Estado. O compromisso de que o valor cristalizado no papel moeda será mantido e garantido no longo prazo representa parte da narrativa estatal, ou seja, ele é o agente garantidor fundamental na economia. A moeda possui, assim, seu lastro, em última instância, no Estado. As criptomoedas (como o bitcoin) problematizam essa narrativa. O lastro desse tipo de economia é a própria comunidade de usuários. Se, antes, o único agente capaz de impor uma narrativa de confiança sobre a economia era o Estado-nação, agora o bitcoin mostra que o lastro pode ser deslocado para a própria comunidade enquanto tal, sem passar por qualquer mediação de algum ente que a represente.

Não é irrelevante nesse sentido que esse sistema digital tenha sido desenvolvido por pessoas ligadas aos movimentos Cypherpunks que, em sua maioria, eram associados às correntes de pensamento anarquistas. Se, como afirmamos em diversos momentos, o desenvolvimento dessas ações não pode ser apreendido como necessidade em direção a qualquer objetivo, sem um telos que dê suporte, organizado pela perspectiva rizomática, ao menos podemos identificar nos agentes que desenvolvem e animam tais circuitos info-territoriais uma profunda vontade em questionar as estruturas e a narrativa do Estado moderno.

Outro sistema de organização possibilitado pelos relacionamentos em rede e que colocam em questão a legitimidade da organização social em Estadosnação é o Movimento dos Indignados, ou 15M. O movimento surgiu na Espanha após uma série de mobilizações nas redes sociais digitais reivindicando reformas políticas, o fim do financiamento público de partidos políticos, a inabilitação para o exercício legislativo de políticos com processos ou condenados, contra o desemprego, a corrupção etc., o que culminou em grandes manifestações e a 
ocupação da Praça Porta do Sol, no centro de Madrid, em 15 de maio de 2011. As manifestações se espalharam por inúmeras cidades espanholas representando a insatisfação pública contra o poder dos bancos, contra a crise e a favor de uma democracia direta.

Seus críticos à direita e à esquerda buscam interpretar o movimento pela falta, pela negação do político como instituído no ocidente. À direita, os movimentos são criticados por não levarem suas demandas para dentro do processo institucional vigente [14]. Mas a esquerda também olha atônita para os movimentos que não se expressam pela miríade de partidos que fixam seus objetivos pela conquista do poder. A insistência em buscar direções dentro da chave predominante na esquerda para tais movimentos pode ser encontrada no recente livro Occupy, organizado pela Boitempo, no qual vemos entre as perguntas que estimulam o pensamento da esquerda a seguinte passagem:

Terão eles possibilidades de criar condições efetivas (político-ideológicas) para o surgimento de novas organizações de classe, capazes de traduzir, no plano da institucionalidade democrática, as medidas necessárias para a realização dos anseios dos indignados, sob pena de frustração irremediável? (HARVEY, et al, 2012, p. 38)

Falta de organização, falta de institucionalização; substituamos pela perspectiva. Sua potência está em recusar o Estado e seu poder coercitivo, sua lógica centralizadora e hierarquizada, o que vai além de uma luta por um espaço no quadro político partidário usual. $\mathrm{O}$ assombro generalizado é que grande parte desses movimentos, ao serem perguntados sobre o próximo passo, resistem em responder "no plano da institucionalidade democrática".

Porém, a organização do $15 \mathrm{M}$ nunca se propôs unitária e unificadora. Nunca pretendeu ser organizadora de um discurso unitário e de uma ação integrada. Com isso, o desenvolvimento do movimento foi justamente o racha entre grupos que entendiam que o movimento deveria avançar para dentro da institucionalidade democrática e outros que o movimento deveria manter seu modelo autonomista. Dentro desse embate, surge o partido Podemos.

Era o que faltava para completar o quadro narrativo dentro da racionalidade estatal. Os meios de comunicação espanhóis rapidamente tomam o par- 
tido como representante prioritário e herdeiro legítimo do Movimento dos Indignados. Os demais participantes do $15 \mathrm{M}$ perdem rapidamente espaço para o grupo que se organiza conforme as representações do Estado moderno. Evidente que esse é um jogo em que os movimentos são mutuamente antecipados, como prova o diálogo entre Pablo Iglesias e Antônio Negri [15], no qual num momento de profunda sinceridade sobre a estratégia de ação do Podemos, Iglesias afirma que sua aposta foi a de uma "liderança midiática" ao mesmo tempo em que sua construção partidária seria aquela que inverteria a lógica do trabalho de base, tão caro ao movimento $15 \mathrm{M}$, para dar prioridade em primeiro plano à disputa eleitoral.

\section{Considerações finais}

A partir das reflexões teóricas e dos exemplos apresentados, pode-se concluir que a narrativa do Estado-nação está em crise, mas ainda está longe de ser batida. As contranarrativas, representadas neste trabalho pelas novas tecnologias e as novas possibilidades de organização em rede, ainda não estão maduras suficientes - e não se sabe se em algum dia estarão - para substituir o mito do Estado na rede simbólica da sociedade contemporânea.

O Estado-nação soube se reinventar ao longo de seus mais de dois séculos de existência e sobreviveu a diversas mudanças tecnológicas e de organização social. Nem mesmo os países socialistas conseguiram se libertar do mito do Estado nacional burguês. "A ilusão nacional”, escreve Carbonaro (2015, p. 32), "foi materializada e internalizada no imaginário coletivo com tamanha força, que permanece até hoje como parâmetro de organização social em todo mundo".

As consequências da nova organização que surge atualmente são incertas e pouco previsíveis, mas exigirão uma nova adaptação para que a narrativa do Estado nação não perca sua legitimidade. $\mathrm{O}$ fim do Estado-nação não parece previsível em um futuro próximo, mas seu surgimento muito possivelmente não era cogitado seriamente algumas décadas antes da Revolução Francesa. Acompanharemos a evolução dessa guerra de narrativas muito atentos e com grande interesse. 


\section{Notas}

[1] Ainda que outro sentido para o termo nação - aplicado também a comunidades políticas que não coincidem com as fronteiras estatais, como a nação curda no Oriente Médio ou a nação basca nos Pirineus - tenha encontrado sobrevida paralelamente ao reforço do Estado-nação, é este último que se fixa no imaginário coletivo como entendimento dominante.

[2] O estabelecimento do início desse ciclo em 1789 refere-se ao universo europeu, já que o processo de independência dos Estados Unidos tem como data simbólica 1776 e também pode ser inserido no quadro das revoluções do período.

[3] O filósofo francês Cornelius Castoriadis (1991, p. 142), em seu livro A instituição imaginária da sociedade, defende que o mundo está "indissociavelmente entrelaçado com o simbólico". Não que tudo seja diretamente símbolo, como ele mesmo alerta, mas muitos dos "produtos materiais sem os quais nenhuma sociedade poderia viver" são impossíveis fora de uma rede simbólica, que é encontrada, primeiramente, na linguagem, mas também, "num outro grau e de uma outra maneira", nas instituições.

[4] O significante é a imagem acústica, uma sequência de fonemas que remetem ao significado, que é o conceito ou ideia de alguma coisa (SAUSSURE, 1993, p. 80).

[5] Barthes (2010, p. 206) refere-se ao primeiro sistema semiológico como "sistema linguístico, a língua (ou os modos de representação que lhe são comparados)", ao qual ele chamou de "linguagem-objeto", já que "é a linguagem de que o mito se serve para construir o seu próprio sistema”, que seria o sistema semiológico segundo.

[6] Barthes (2010) fala apenas da absorção do mito em uma sociedade, não em relação ao mito nacional.

[7] Weber (2004) não faz referência à comunidade imaginada do Estado, mas trata da forma como o Estado é capaz de impor regras e comportamentos, a gestão de condutas, o que garantiria sua existência. A aproximação entre a definição de Weber, mais próxima da materialidade do Estado, e o simbolismo que o legitima, como tentamos explicitar acima, nos parece bastante coerente e importante para a compreensão de como as bases do Estado, tanto em sua materialidade como em seu simbolismo, serão questionados pela organização em rede.

[8] Deleuze (2008) vai chamá-la de sociedade de controle e desenvolver outros conteúdos com base nos textos de Foucault.

[9] A separação entre a lógica disciplinar e a lógica da governamentalidade não é da ordem exclusivamente histórica. Elas se interpenetram e estão presentes ao mesmo tempo, na visão de Foucault, no espaço de produção e reprodução social.

[10] Que não é identificado com os organismos de repressão.

[11] Vimos nos últimos anos como pode tornar-se ainda mais difícil coordenar a saída de uma crise recessiva sem a capacidade de gestão de políticas macroeconômicas como no caso dos países da união europeia.

[12] Bitcoin é uma moeda digital criada em 2009 por Satoshi Nakamoto. O nome também se refere ao programa código aberto que ele projetou para usar a moeda, e a rede peer-to-peer que ele forma. Diferente da maioria das moedas, bitcoin não depende em 
confiar em nenhum emissor centralizado. Bitcoin usa banco de dados distribuído pelos nós da rede peer-to-peer para registrar as transações, e usa criptografia para prover funções básicas de segurança, como certificar que bitcoins só podem ser gastas pelo dono, e evitar gastos duplos.

O projeto de Bitcoin permite propriedade e transferências anônimas de valores. Bitcoins podem ser salvas em computadores na forma de um arquivo carteira, ou em serviços de carteira provido por terceiros; e em ambos os casos bitcoins podem ser enviadas pela Internet para qualquer pessoa que tenha um endereço de Bitcoin. A topologia P2P da rede Bitcoin e a ausência de uma entidade administradora central torna inviável que qualquer autoridade, governamental ou não, manipule o valor de bitcoins ou induza inflação "imprimindo" mais notas. (WIKIPEDIA. Disponível em:<http://pt.wikipedia.org/wiki/ Bitcoin>. Acesso em: 17 nov 2018)

[13] Esforços têm sido feitos para taxar as saídas de recursos da economia bitcoin para moedas fiduciárias, como o dólar ou o real; no entanto, o efeito tem sido justamente o oposto daquele esperado. À medida que aumentam as tributações para converter bitcoins em moedas fiduciárias menos as pessoas realizam a conversão. Com isso, grande parte das transações é realizada sem que sejam sequer computadas por qualquer sistema nacional de controle de tributos.

[14] Discurso inclusive muito comum de que a ordem democrática vigente é capaz de processar as demandas dos atores desde que aceitem os limites impostos pelas instituições.

[15] Fonte: https://www.youtube.com/watch?v=BOpTvdOXF9U

\section{Referências}

ANDERSON, Benedict. Comunidades imaginadas. São Paulo: Companhia das Letras, 2009.

BARTHES, Roland. Mitologias. Rio de Janeiro: Difel, 2010.

BAUMAN, Zygmunt. Comunidade. Rio de Janeiro: Zahar, 2003.

BOBBIO, Norberto. Dicionário de política. Brasília: Editora UnB, 1998.

CASTORIADIS, Cornelius. A instituição imaginária da sociedade. Rio de Janeiro: Paz e Terra, 1991.

DELEUZE, Gilles. Conversações. São Paulo: Editora 34, 2008.

FOULCAUT, Michel. Vigiar e Punir: nascimento da prisão. Petrópolis: Vozes, 2004.

FOULCAUT, Michel. Segurança, Território e População. São Paulo: Martins Fontes, 2008.

GELLNER, Ernest. Nações e nacionalismo. Lisboa: Gradiva, 1993.

HARVEY, David. et al. Occupy: Movimentos de protesto que tomaram as ruas. 
São Paulo: Boitempo Editorial, 2015.

HOBSBAWM, Eric.; RANGER, Terence. (Orgs.). A invenção das tradições. São Paulo: Paz e Terra, 2002.

JODELET, Denise. As representações sociais. Rio de Janeiro: EDUERJ, 2001.

MOSCOVICI, Serge. Representações sociais: investigações em psicologia social. Petrópolis: Vozes, 2010.

SAUSSURE, Ferdinand. Curso de linguística geral. São Paulo: Cultrix, 1993.

SCHWARCZ, Lilia M. Apresentação. In: ANDERSON, Benedict. Comunidades imaginadas. São Paulo: Companhia das Letras, 2009.

SMITH, Anthony D.. A identidade nacional. Lisboa: Gradiva, 1997.

WEBER, Max. Economia e sociedade: fundamentos da Sociologia Compreensiva. Vol.1. 4. ed. Brasília: Editora UnB, 2004.

WEBER, Max. A Ética Protestante e o "Espírito" do Capitalismo. São Paulo: Companhia das Letras, 2006. 